\title{
"Onde fica a casa do meu amigo" : agência e agenciamento de objetos no filme de Abbas Kiarostami
}

Film analysis of 'Where is the friend's home?': agency and the agency objects

\section{Marília Milhomem Moscoso Maia e Martina Ahlert}

\section{(2) OpenEdition}

Journals

Edição electrónica

URL: http://journals.openedition.org/aa/1657

DOI: 10.4000/aa. 1657

ISSN: 2357-738X

Editora

Programa de Pós-Graduação em Antropologia Social (UnB)

Edição impressa

Data de publição: 1 julho 2017

Paginação: 87-109

ISSN: 0102-4302

\section{Refêrencia eletrónica}

Marília Milhomem Moscoso Maia e Martina Ahlert, «"Onde fica a casa do meu amigo" : agência e agenciamento de objetos no filme de Abbas Kiarostami», Anuário Antropológico [Online], v.42 n.1 I 2017, posto online no dia 01 junho 2018, consultado o 28 abril 2021. URL: http:// journals.openedition.org/aa/1657 ; DOl: https://doi.org/10.4000/aa.1657

\section{(c)}

Anuário Antropológico is licensed under a Creative Commons Atribuição-Uso Não-Comercial-Proibição de realização de Obras Derivadas 4.0 International. 


\title{
"Onde fica a casa do meu amigo": agência e agenciamento de objetos no filme de Abbas Kiarostami
}

\author{
Marília Milhomem Moscoso Maia \\ UFMA \\ Martina Ahlert \\ UFMA
}

In memoriam de Abbas Kiarostami

O cinema tem se mostrado relevante no que diz respeito à possibilidade de compreensão das articulaçôes entre culturas, realidades e processos históricos. Trata-se também de uma ferramenta de discurso, que nos direciona para a construção de um olhar crítico e para uma alfabetização entre linguagem e imagem. Por muito tempo se negou o cinema como objeto de pesquisa, pois a "Ciência" sempre fez questão de propagar o seu viés positivista e sua pretensa capacidade de objetivar a realidade em favor de um conhecimento tido como exato. ${ }^{1}$ Nessa perspectiva, segundo Pires (2011), esta arte era tida como algo que falseava a realidade, algo trivial, que náo se encaixava em uma lei interna ou na constituição do fato e da realidade, além de não produzir dados concretos.

O século XX transformou o cinema em um grande laboratório, abandonando a vertente exclusiva de sua compreensão como mero divertimento. Tal aspecto impactou "a reconstrução dos paradigmas científicos das ciências humanas que há muito buscavam narrar, explicar, apreender os acontecimentos e os fenômenos psicológicos, históricos e sociais que envolvem os homens em suas relaçôes" (Pires, 2011:1). Assim, a narrativa fílmica, bem como as imagens, passou ser utilizada pelas ciências sociais também como material de pesquisa.

Os historiadores orais e os antropólogos foram os primeiros a compartilhar o entendimento do cinema e do audiovisual em geral como instrumento de observação, de transcrição e de interpretação das realidades sociais, além das funçóes já empregadas em termos de ilustração e difusão de pesquisas (Pires, 2011:1).

O recolhimento imagético começou a ser utilizado após a Segunda Guerra Mundial pela antropologia que se pautava em uma 'urgência', "a necessidade de registrar, antes que fosse tarde, as atividades e os comportamentos humanos em vias de desaparecimento com o advento e a difusão da modernidade" (Pires, 2011:1). Desta perspectiva inicial, outras análises se desdobraram, pensando o cinema como forma de registro, de representação ou mesmo de questionamento da realidade. 
Não apenas os filmes retratam aspectos sobre sociedade e cultura, mas a própria cinematografia, no Ocidente, se torna uma instituição cultural na medida em que aglutina cuidados especiais, regulamentação e pessoal especializado. "É nesses santuários especializados que os documentos, registros, relíquias e corporificaçóes das mais altas realizaçôes humanas são preservados e a 'arte' ou 'cultura' é mantida viva” (Wagner, 2010:55). Portanto, o cinema nos oferece um escopo de exploraçáo e aprofundamento não só teórico, mas de compreensão cultural, artística e visual. ${ }^{2}$ Graeme Turner diz que

o cinema não reflete nem registra a realidade; como qualquer outro meio de representação, ele constrói e "representa" seus quadros de realidade por meio de códigos, convençóes, mitos e ideologias de sua cultura, bem como mediante práticas significadoras específicas desse meio de comunicação. Assim como o cinema atua sobre os sistemas de significado da cultura para renoválos, reproduzi-los ou analisá-los - também é produzido por esses sistemas de significados. O cineasta [...] é o bricoleur, uma espécie de faz tudo que realiza o melhor que pode com o material que tem à máo. $\mathrm{O}$ cineasta usa os repertórios $\mathrm{e}$ convençōes representacionais disponíveis na cultura a fim de fazer algo diferente, mas familiar; novo, mas genérico; individual, mas representativo (1997 apud Meleiro, 2006:17-18).

A proposta deste trabalho, baseada na possibilidade de ter obras cinematográficas como recorte de análise, é discorrer sobre a agência e o agenciamento dos objetos utilizados na trama Onde fica a casa do meu amigo, do iraniano Abbas Kiarostami, produzida em 1987. Estes conceitos estáo ligados às concepçóes de objeto, coisa e sujeito e, para entendê-los, lançamos mão das contribuições de Tim Ingold (2005, 2012, 2013) e Bruno Latour (2012). Ingold ultrapassa a noção comumente estabelecida de "objeto", propondo o uso da noção de "coisa" como algo fluido, perpassada por fluxos vitais e integrada às dinâmicas da vida e do meio ambiente. Por sua vez, Latour questiona a divisão entre sujeito (humano) e objeto (náo humano), pois acredita na necessidade de irmos além da separação entre sujeitos autônomos e objetos inertes e focarmos as possibilidades de relação entre humanos e não humanos. A partir desses autores, é possível falar em agência ou agenciamento, na medida em que objetos e coisas não são entidades passivas, mas elementos atuantes nas relações sociais.

O filme Onde fica a casa do meu amigo (no original: Khane-ye doust kodjast?) foi escolhido por apresentar uma narração que nos possibilita variadas interpretaçôes, bem como pela relação que Kiarostami desenvolve entre cinema e infância (Bergala, 2008). Na película, o autor rompe com o processo comum de representar o Oriente como lugar estranho ou exótico e nos aproxima da 
complexa cultura iraniana por intermédio de cenas da vida doméstica, como crianças brincando na rua, mulheres lavando roupas, um bebê que chora, a negociação entre um ferreiro e um carpinteiro etc. Todo este contexto oferece um modo alternativo de ver as coisas sob a ótica da experiência poética entre cinema, universo infantil e vivência pessoal. Kiarostami usa um jogo de cena que traz à tona elementos de uma ficçáo com rastros do mundo real, como as censuras e privaçóes; o uso de protagonistas infantis para descortinar temas da interdição; a submissão entre adultos e crianças; o poder existente nas relaçóes professor-aluno e mãe-filho; e a relação entre humanos e não humanos (objetos).

Onde fica a casa do meu amigo é um dos filmes produzidos quando Kiarostami foi convidado pelo diretor do Instituto para o Desenvolvimento Intelectual de Crianças e Jovens Adultos (Kanun) a assumir o departamento de cinema da instituição. Mesmo com a Revoluçáo Islâmica de 1979, ${ }^{3}$ o departamento sob a direção de Kiarostami se destacou ao produzir notáveis filmes (como a trilogia da qual Onde fica a casa do meu amigo participa, com $A$ vida continua e Através das oliveiras). O filme aqui analisado é o que dá projeçáo internacional ao diretor, algo fundamental quando suas películas passam a não ser exibidas no Irã por enfatizarem temas considerados polêmicos, como gênero e relacionamentos amorosos, por exemplo.

O filme analisado neste artigo retrata a história de amizade e cumplicidade de duas crianças. A trama se desenvolve a partir do momento em que Ahmed pega por engano o caderno de Mohammed, um colega de escola. Quando percebe, Ahmed parte em uma jornada em busca da casa do amigo para devolver seu caderno. Sua missáo se complica porque, se Mohammed náo tiver o caderno com os trabalhos de casa feitos no dia seguinte, receberá um castigo severo do professor. O filme acompanha os deslocamentos e a frustração de Ahmed, que termina por voltar para casa e fazer as tarefas no caderno de Mohammed. Onde fica a casa do meu amigo foi escolhido para compor a analítica deste artigo por abordar uma história simples, mas sublime nas maneiras de captar e representar a infância e sua vulnerabilidade em uma sociedade adultocêntrica, que não percebe e não escuta a criança.

A perspectiva do filme nos ajuda a compreender como um simples caderno, objeto tido como inanimado, passa a influenciar profundamente as açóes e as relaçóes sociais de Ahmed, personagem central do enredo. A partir do encontro com o caderno, vemos o movimento da criança entre diferentes espaços, seu próprio processo de transformação e, desta forma, a subversão de determinada noção de infância que condena as crianças a um lugar de subserviência. Escolhemos o caderno, entre outros objetos que aparecem na trama, porque ele 
coloca em evidência a relação entre adulto e criança e é o objeto que motiva o deslocamento de Ahmed, ao mesmo tempo em que se movimenta com ele.

\section{Onde fica a casa do meu amigo e as culturas infantis}

Em Onde fica a casa do meu amigo, Kiarostami nos apresenta Ahmed, um garoto que traz na pasta, por engano, o caderno de um amigo de escola. $\mathrm{O}$ universo infantil é central na trama, estando presente na simples ação de pular uma poça d'água, de subir em lugares altos ou de correr nos arredores da escola. É no cenário das atividades desempenhadas pelas crianças que Mohammed, brincando de correr, machuca o joelho. Ahmed mostra um sentimento de solidariedade e ajuda o amigo a limpar o ferimento.

\section{Figura 1 - Ahmed ajudando a limpar o ferimento de Mohammed}

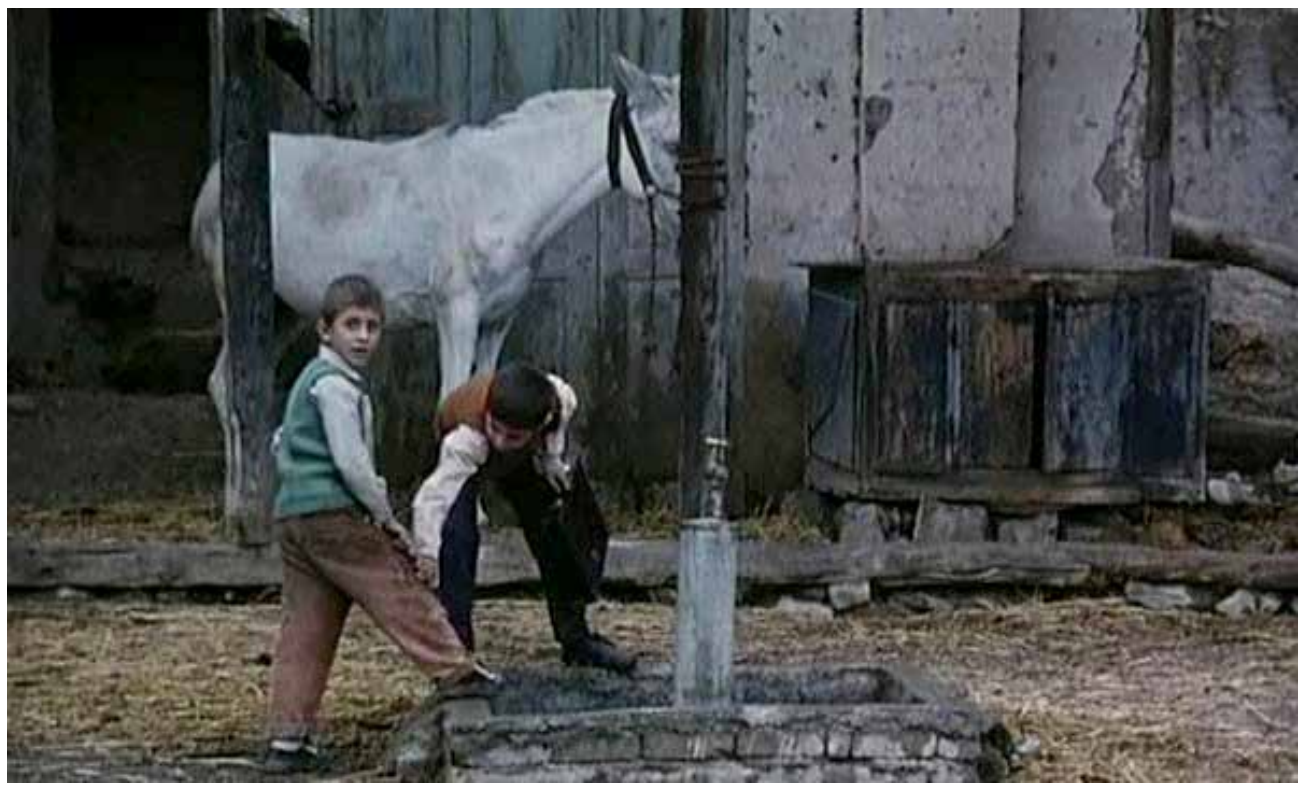

Fonte: Abbas Kiarostami, 1987

Ao colocar em primeiro plano o universo infantil, Kiarostami anuncia que as crianças dão movimento aos processos de sociabilidade e que, por intermédio de interações, modificam as rotinas sociais. As crianças têm, portanto, participação na cultura que compartilham. Se tomarmos como ponto de partida o conceito de cultura de Clifford Geertz (2008:15) - que, a partir da construção de uma noção de cultura baseada na semiótica, afirma que "o homem é um animal amarrado a teias de significados que ele mesmo teceu” -, estaremos diante do 
desafio de compreender as crianças como seres que atribuem significado a seus atos e comportamentos, criam significados novos e estabelecem relaçôes sociais.

A definição de Geertz sugere que cultura é o compartilhar de construçóes simbólicas. Para o autor, náo interessa a interpretação e explicação dos fatos de forma isolada, mas a importância do conjunto, de forma que

a cultura não é um poder, algo ao qual podem ser atribuídos casualmente os acontecimentos sociais, os comportamentos, as instituiçóes ou os processos; ela é um contexto, algo dentro do qual os símbolos podem ser descritos de forma inteligível isto é, descritos com densidade (Geertz, 2008:10).

Esta noção ampla de cultura e de uma antropologia que "se dedica a entender o ponto de vista daqueles sobre quem e com quem fala” (Cohn, 2005:8) pode ser útil para compreender o que se chama de cultura das crianças ou culturas infantis. Mas por que falar de culturas infantis ou até mesmo de uma antropologia da criança? Não seria um problema partir de uma noção ampla de cultura, como a apontada por Geertz, para uma noção fechada de uma cultura infantil? A resposta se encontra no fato de que é possível pensar em "um modelo analítico [que] permite entender as crianças por si mesmas" e "escapar daquela imagem em negativo, pela qual falamos menos das crianças e mais de outras coisas" (Cohn, 2005:9). Nesse sentido, poderíamos pensar em uma proposta de estudo que se alicerça no pressuposto de que, "para o que constitui as infâncias, o que as crianças fazem e criam quando estão juntas” (Coutinho, 2003:4) ou sozinhas é fundamental. "Considerar que ser criança implica ações que são próprias dos seus saberes, o conhecimento destes exige, então olhares múltiplos, que possibilitem ao adulto que a observa a contemplação de suas diversas formas de manifestação" (Coutinho, 2003:2).

As crianças manifestam suas experiências ou recriam situaçóes cotidianas por meio de variadas expressóes, de diversas linguagens, utilizando os elementos culturais que as cercam. Nesse processo, o brinquedo, as brincadeiras, os jogos, o vestuário, os gestos e o palavreado serão apreendidos por intermédio da relação criança-criança ou com os grupos de pares. A sociabilidade infantil existe em todas as culturas; o que varia de uma cultura para outra sáo os valores locais, a linguagem, os costumes, as noçóes do que é aprendido na infância, do que é considerado feminino e masculino, a construção da identidade etc. Segundo Clarice Cohn (2005), em todos os lugares existem crianças e se pode estudálas comparando suas experiências e vivências; no entanto, essas experiências e vivências são diferentes para cada lugar, por isso precisamos entendê-las em seu contexto sociocultural. Portanto, não existe uma criança ou uma infância 
universal. Tentar enquadrar as diversas infâncias como algo único evidencia a arbitrariedade de ver as coisas a partir de um ponto de vista restrito, que distancia, deturpa e mascara as experiências.

Autores que dialogam com Cohn, como Antonella Tassinari (2009), provocam uma noção unívoca de infância a partir da comparação entre experiências sociais e culturais. Nesse sentido, por exemplo, diversos grupos indígenas brasileiros apontam para cenários onde as crianças não são vistas como um mundo à parte do mundo adulto, ou mesmo como seres passivos diante das questóes tidas como fundamentais ou centrais à sociedade. Por intermédio da comparação entre infâncias também surge uma problematização em torno da ideia de escola, na medida em que, nas sociedades capitalistas, existe uma redução da ideia de criança à de aluno, que precisa seguir uma rotina de estudos elaborada pelos adultos (Tassinari, 2009). No Ocidente, construímos uma noção de criança como um ser diferente, projetando demasiadamente sobre ela estruturas de contenção por meio da educação e de valores.

Estas separaçóes e fronteiras foram criadas na importância que se atribuiu ao processo de aprendizagem, que, segundo Philippe Ariès (1978), nos fez constituir o mundo infantil como distanciado e mesmo inocente ou incompleto perto do mundo adulto. As crianças foram transportadas para o meio dos adultos e tratadas sob um silenciamento, um excesso de precauçóes e um jogo de puniçóes e responsabilidades - o que Michel Foucault (2015) chamou de discurso interno da instituição. A criança tornou-se um problema público, pois precisava ser contida e vigiada e, se porventura viesse a cometer uma infração, precisaria ser punida de maneira exemplar. Profissionais com um saber especializado se dirigiriam aos adultos para que estes criassem uma rede de instrumentos e de mecanismos para regular o corpo infantil e juvenil.

Os médicos se dirigem aos diretores de estabelecimentos e aos professores, também dão conselhos às famílias; os pedagogos fazem projetos e os submetem às autoridades; os professores se voltam para os alunos, fazem-lhes recomendaçóes e para eles redigem livros de exortaçáo, cheios de conselhos médicos e de exemplos edificantes (Foucault, 2015:31-32).

Ahmed, na instituição escolar, é o que Tassinari (2009) chama de criançaaluna, reconhecida de imediato pela relação hierárquica com o professor. $\mathrm{Na}$ escola, ele não tem liberdade e autonomia. $\mathrm{O}$ filme faz uso de uma representação de ambiente escolar em que as crianças não participam nem são atores plenos de sua aprendizagem. Esta é condicionada a um modelo onde o professor é o elemento central do processo de ensino. 
Figura 2-Ahmed

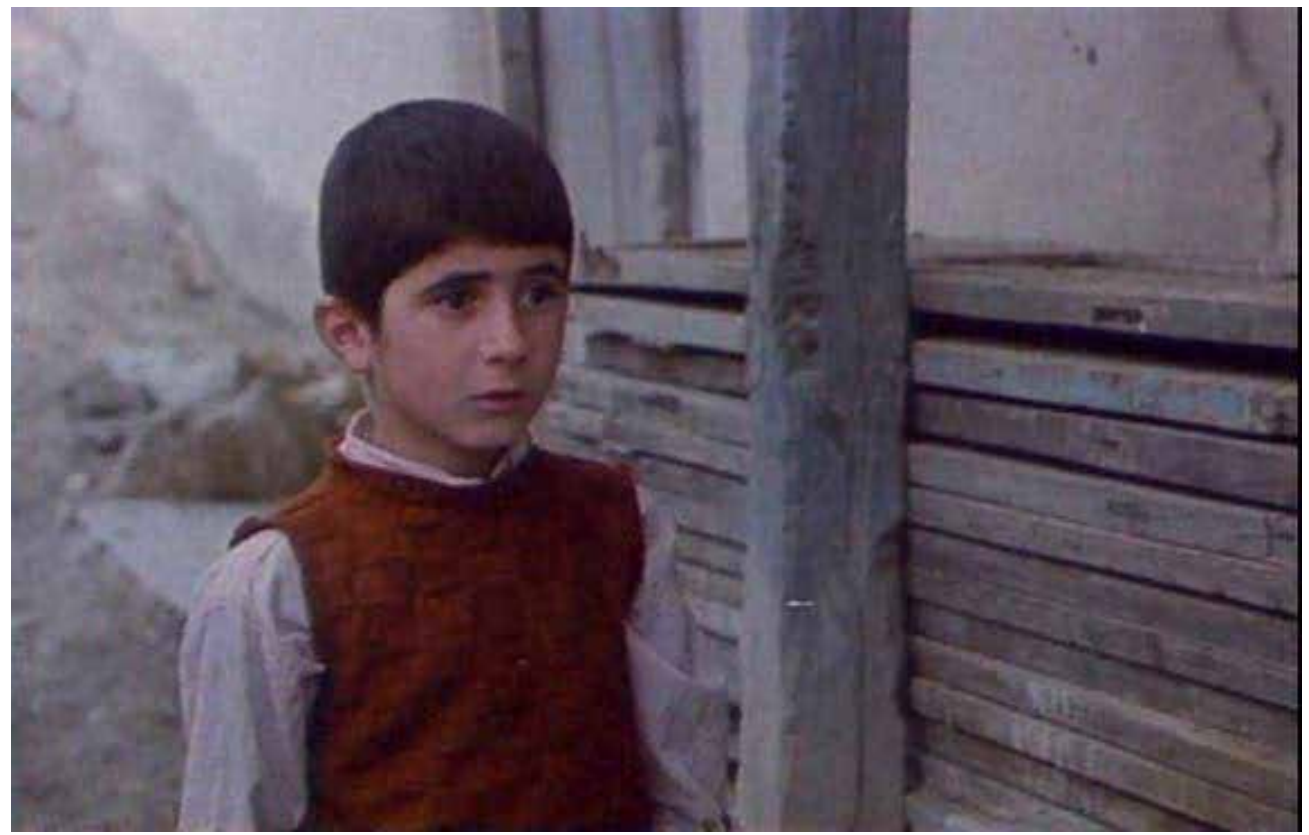

Fonte: Abbas Kiarostami, 1987

Kiarostami traz para a sua narrativa a representação de uma sociedade iraniana tradicional. Nessa sociedade, quase não se percebe a criança e, quando ela chega a ser percebida, é para receber ordens dos adultos. Para os adultos do filme, como o professor, os pais e o avô de Ahmed, as crianças devem aprender desde cedo a obedecer sem fazer muito caso. $\mathrm{O}$ amor e o carinho entre adultos e crianças são inexistentes na trama do diretor, bem como a afetividade e a própria comunicação. A afetividade, a cumplicidade e a comunicação somente terão equilíbrio no par criança-criança.

$\mathrm{Na}$ descrição da escola, é visível um ambiente pobre de recursos, repressor do corpo infantil e despótico, centrado na figura de um professor que preza pela organizaçáo das atividades no caderno. Todas as atividades devem ser feitas nesse caderno, e não há espaço para a quebra de protocolos. Mohammed já tinha sido alertado duas vezes por ter feito suas atividades em um papel avulso; se houver uma terceira vez, ele será expulso por não cumprir as ordens do professor. Rígido, o professor ralha com Mohammed na frente de todos os colegas e só para quando o primo de Mohammed diz que ele dormiu na sua casa, esquecendo o caderno lá. $\mathrm{O}$ professor encerra a discussão dizendo que não haverá uma próxima vez. 
Figura 3 - Professor, Mohammed e Ahmed

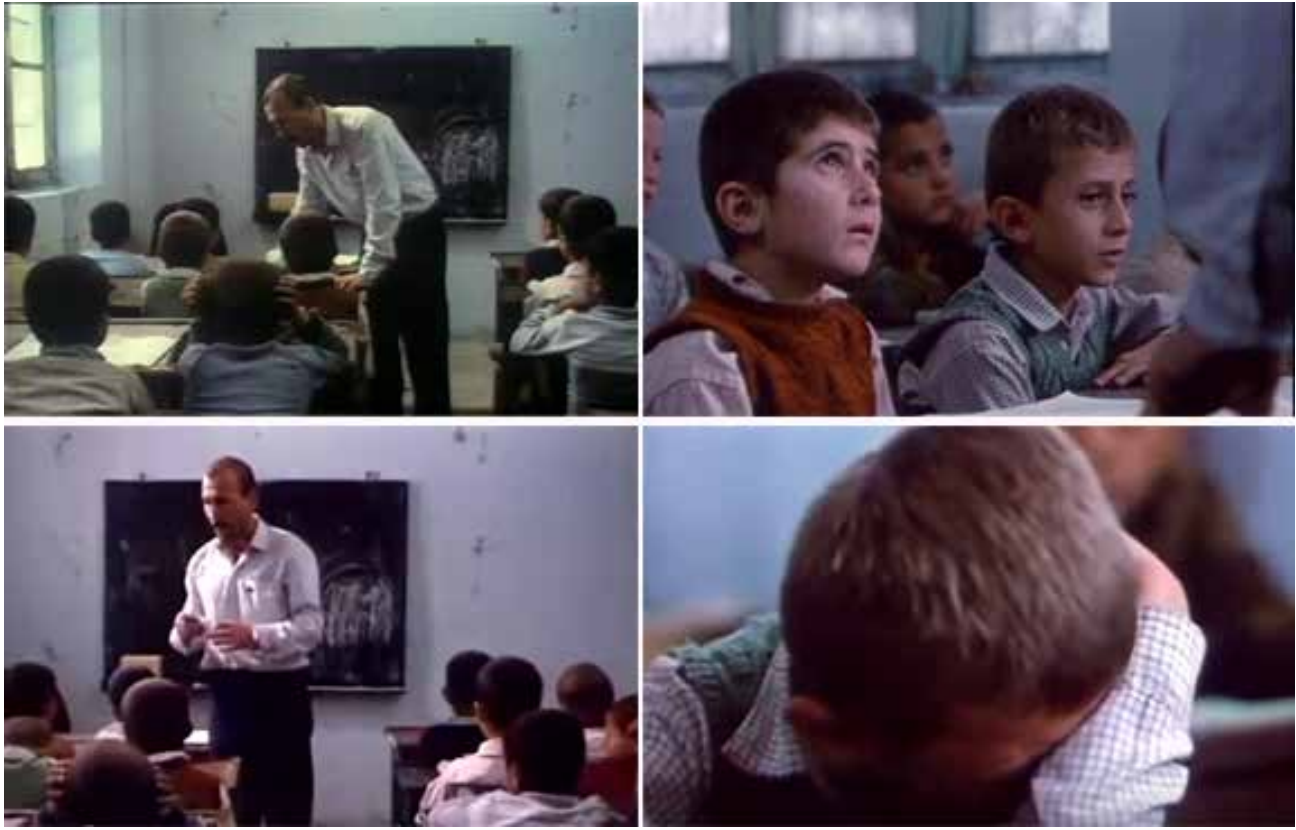

Fonte: Abbas Kiarostami, 1987

No filme, ao término das aulas, todos os meninos saem correndo para suas casas, mas Mohammed cai e machuca o joelho. É Ahmed que o ajuda a levantar. Nesta cena, Kiarostami representa uma cultura infantil de cumplicidade. E é nesse momento que se complica toda a trama, quando Ahmed pega, por engano, o caderno de Mohammed.

Chegando em casa, Ahmed precisa atender uma série de pedidos de sua máe: pegar a fralda do bebê, buscar água morna para a mamadeira e balançar a rede de seu irmão mais novo. Quando finalmente ele se senta para responder aos exercícios escolares, se dá conta de que pegou o caderno de Mohammed, o que o faz lembrar-se das palavras duras do professor. Ahmed tenta explicar a situação para a mãe, mas ela não o escuta. Nesta cena, Kiarostami nos lembra da arrogância dos adultos em relação às crianças e dos falsos sentimentos de superioridade. Segundo Inez e Faria (2006), a representação da falta de diálogo de filho e mãe náo é um exemplo insignificante. Ela existe tanto na cultura iraniana quanto na cultura brasileira. 
Figura 4 - Ahmed e sua mãe

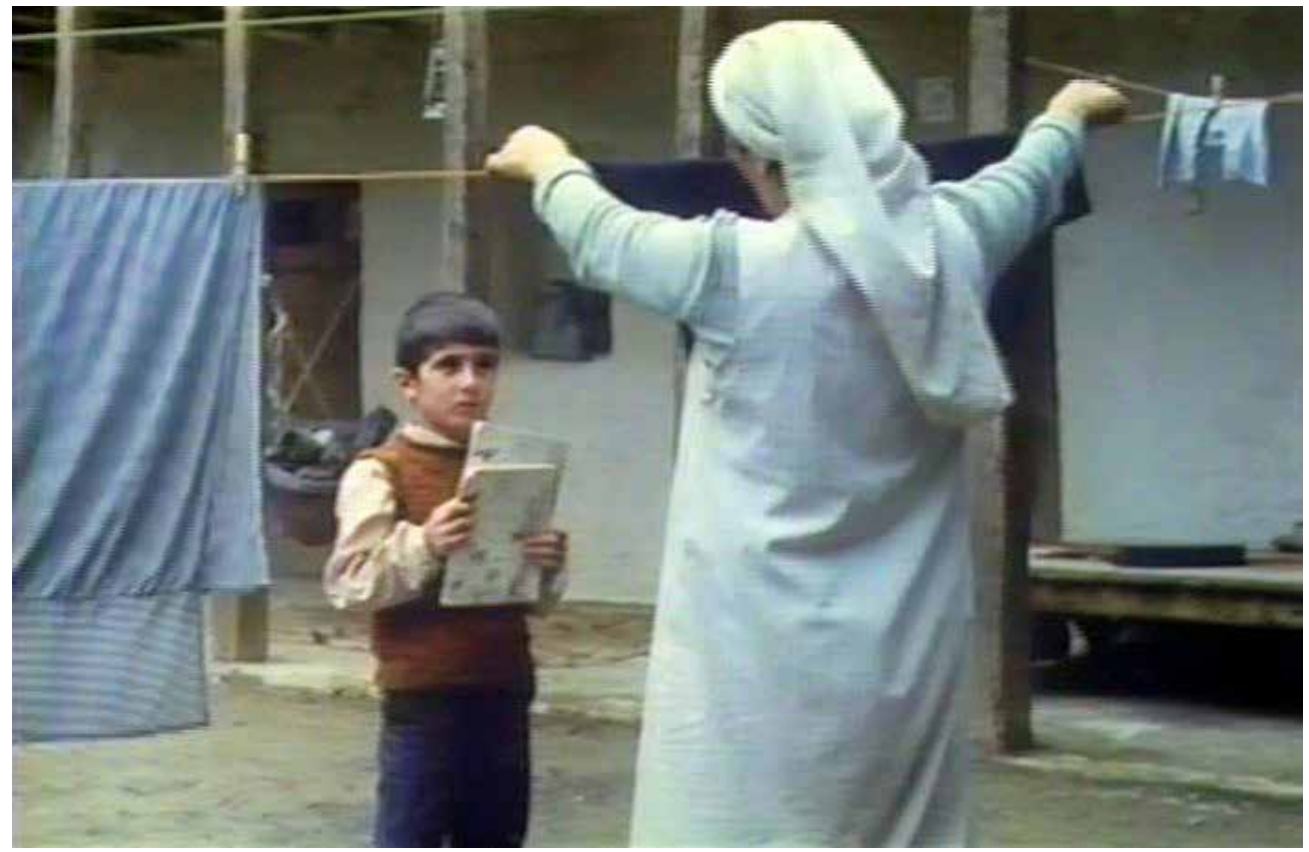

Fonte: Abbas Kiarostami, 1987

O diretor iraniano representa uma infância que busca formas de fugir dos sentimentos de repressão e controle impostos pelos adultos. Ele repudia um mundo "adultocêntrico", repressor dos sentimentos, da afetividade e da cumplicidade. Para tecer tais questionamentos, Kiarostami representa o universo infantil a partir de uma separaçáo entre o mundo da criança e o mundo do adulto. Seguindo a crítica de Bruno Latour (2012), que nos inquire sobre o pensamento baseado na dualidade, esta separaçáo de mundos pode ser compreendida como parte da construçáo das dicotomias, onde há um "constante empenho de algumas pessoas em desenhar fronteiras que as separem de outras" e onde se considera que "a principal característica desse mundo consiste em reconhecer, independentemente de quem as traça e com quais ferramentas, a existência inquestionável das fronteiras" (Latour, 2012:51).

De forma sutil, Kiarostami nos ensina que Ahmed aprende a lidar com a instituição escolar e familiar e que a sua saga de entregar o caderno para o seu amigo - a trajetória, os percursos, as pessoas que ele encontra pelo caminho culmina em uma aprendizagem que supera a do espaço escolar. É, portanto, nesta aprendizagem fora do muro escolar e na relação entre humanos e não humanos (objetos) que Ahmed supera a condição de criança-aluno e a repressão 
sobre o seu corpo e suas vontades, tornando-se uma criança que compreende as regras e o jogo imposto pelo mundo adulto.

Ahmed revela uma impressionante "capacidade de objetividade na avaliação de conjunturas e no estabelecimento de estratégias para resolver problemas práticos" (Tassinari, 2009:276) na medida em que gerencia as tarefas que os adultos lhe impóem com a tentativa de devolver o caderno de seu amigo. A partir do filme, podemos dizer que as crianças contribuem ativamente para a continuidade e também para a mudança social. Essa sociabilização irá se construir solidamente na relação crianças-crianças e nas conexôes que elas próprias fazem com "coisas que não são, em si mesmas, sociais" (Latour, 2012:23), por exemplo, a relação entre criança e objeto. A cada instante, as crianças estabelecem uma forma de conexão com objetos e se lançam para experiências novas, que alteram quem elas são.

Se Kiarostami traz à trama a instituição escolar e familiar baseada em uma cultura iraniana repressora e despótica dirigida às crianças, ele também inova, ao romper esta representaçáo colocando o personagem Ahmed como uma criança atuante. Ele "interage ativamente com os adultos e as outras crianças, com o mundo, sendo parte importante na consolidação dos papéis que assume e de suas relaçôes" (Cohn, 2005:28) a partir do momento em que parte em uma jornada para devolver o caderno de seu amigo.

\section{Agência e agenciamento dos objetos no filme}

Onde fica a casa do meu amigo se desenvolve a partir da jornada heroica na qual Ahmed se lança para devolver o caderno de Mohammed. Nesse eterno vaivém do personagem, parece que o caderno age sobre ele e ele também age sobre o caderno. Este objeto modifica toda uma situação cotidiana, tornando-se um ator ao "fazer coisas 'no lugar' dos atores humanos" (Latour, 2012:109). Ou seja, enquanto no senso comum é apenas um objeto inanimado, na narrativa cinematográfica de Kiarostami o caderno funciona como "coisa" (Ingold, 2012), por agir como uma entidade humana sobre o cotidiano e as relações de Ahmed.

Além de colocar-se como fio condutor da trama, o caderno surge como agente, aquilo que interage e explica os poderes da sociedade, as relaçóes hierarquizadas, o exercício de poder e a materialidade de desigualdades. Kiarostami utiliza o objeto para descortinar temáticas profundas como controle, poder e opressão que o mundo adulto instaura nas crianças. Alguns autores contemporâneos, como Latour (2012) e Ingold (2013), nos ajudam a pensar nas relaçóes traçadas entre pessoas e objetos, onde "em vez de sujeitos e objetos existem 'quase-objetos' e 'quase-sujeitos', conectados em redes relacionais”' (Ingold, 2011:11). 
Os objetos surgem de súbito como aquilo que explica a paisagem variegada pela qual começamos, os poderes supremos da sociedade, as notórias assimetrias, o rude exercício do poder. É dessa surpresa que os sociólogos de associações preferem partir, em vez de considerar, como muitos de seus colegas, que a questão obviamente está encerrada, que os objetos não fazem coisa alguma sequer comparável ou mesmo conectável à ação humana e que, às vezes, "expressam” relações de poder, "simbolizam" hierarquias sociais, "agravam" desigualdades sociais, "transportam" o poder social, "objetivam" a igualdade e "materializam relações de gênero" (Latour, 2012:110).

Para Latour, qualquer curso humano de ação se relaciona com um objeto e é impossível separar o material do social. Existe uma relação inextricável entre objeto e sujeito, estabelecendo assim uma conexão e uma trajetória de existência de ambos. Um simples objeto pode estabelecer conexóes, movimento e ação. Os objetos transformam-se em "mediadores, ainda que por instantes, e logo aparecem de novo graças ao knowhow, ao hábito ou ao desuso" (Latour, 2012:120). ${ }^{5}$ Entender os objetos como mediadores é levar em conta que eles "transformam, traduzem, distorcem e modificam o significado ou os elementos que supostamente veiculam" (Latour, 2012:65).

Nesse sentido, o caderno na ficção de Kiarostami se transforma em uma cadeia complexa de mediação, onde o autoritarismo, a cumplicidade entre crianças e a relação despótica entre crianças e adultos se deslocam a cada instante. Por um lado, o caderno se converte em registro, mediação, verificação e avaliação da aprendizagem por meio da escola e do professor - quando pode ser percebido como algo banal, como um simples registro ou um instrumento de controle. Por outro lado, como mediador, ele se converte em um agente complexo quando o garoto Ahmed sai em uma aventura, funcionando como uma forma de falar sobre a sua relação com o amigo Mohammed. Na narrativa, portanto, o caderno não apenas transmite um significado social - na medida em que explica o estado das relaçóes entre criança-adulto, criança-aluno, criança-objeto e criança-criança -, mas enseja movimento e novas conexóes. Nem Ahmed nem o caderno são elementos inertes nesta trama.

Os objetos também alteram os modos de existência de uma multidão ou unicamente de um sujeito. O que Latour (2012) chama de objeto e de conexóes, Ingold (2013) chama de material ou follow the materials (isto é, material ou siga os materiais). Vale lembrar que Ingold e Latour apresentam visóes diferentes sobre este processo, embora ambos destaquem a importância de romper com a dicotomia entre sujeito e objeto. Ingold (2012) propóe uma crítica à visão de Latour sobre a noção de objeto, de rede, e à teoria do ator-rede a partir do 
desenvolvimento de conceitos de uma antropologia ecológica, além de considerar a diferenciação entre objeto e coisa. Segundo Ingold (2012), "coisa" é algo fluido, que conecta vida e ambiente.

Para o autor (2013:313), trata-se de um processo "sobre as maneiras em que as substâncias de todos os tipos, animadas por forças cósmicas e com propriedades variáveis, misturam e se fundem com outras na geração de coisas". ${ }^{6}$ Vivemos em um mundo de formas e de objetos, as relaçóes entre pessoas e coisas são guiadas pelo pensamento de que o mundo material não é subserviente à concepção humana. Assim, o teórico defende que o mundo é composto por coisas e não por objetos. Sua crítica não trata apenas da diferenciação entre objetos e coisas, ou da vitalidade dos materiais ou da matéria, mas da agência dos objetos.

A agência dos objetos, também percebida como a imaterialidade do material ou, simplesmente, as coisas vivas, trata da inserção de coisas inanimadas na teoria social. Para Ingold, a agência dos objetos, na realidade, é um problema justamente por não existirem objetos, somente coisas - por isso o autor sugere pensar em agência náo como uma força interior ao objeto, mas como movimento que acontece porque a coisa é colocada nas dinâmicas e nos fluxos da vida.

Logo se não existem objetos, mas somente coisas o perigo se encontra no fato de se atribuir a agência dos objetos, no lugar da vida das coisas, resulta na armadilha de considerar as coisas como objetos, retirando-lhes vida e, consequentemente, negando-se os processos de vida inerentes às coisas (Merencio, 2013:198).

De posse do caderno, o pequeno herói Ahmed se dirige a uma vila chamada Poshteh, desobedecendo às ordens da mãe de ficar em casa e fazer os seus deveres. O menino sai escondido, ziguezagueando uma íngreme montanha em direção ao vilarejo. Começa, assim, a saga do pequeno para localizar a casa de seu amigo. Ao longo do percurso de Ahmed, Kiarostami nos introduz uma topografia do lugar, mostrando uma paisagem repleta de declives, montanhas, barrancos, árvores, escadarias e casas. Ahmed anda por entre becos desconhecidos até que encontra uma senhora e pergunta se ali mora alguém chamado Mohammed Nematzadeh. É quando o menino descobre que, no vilarejo, existem vários distritos. 
Figura 5 - Ahmed indo em direção ao vilarejo Poshter

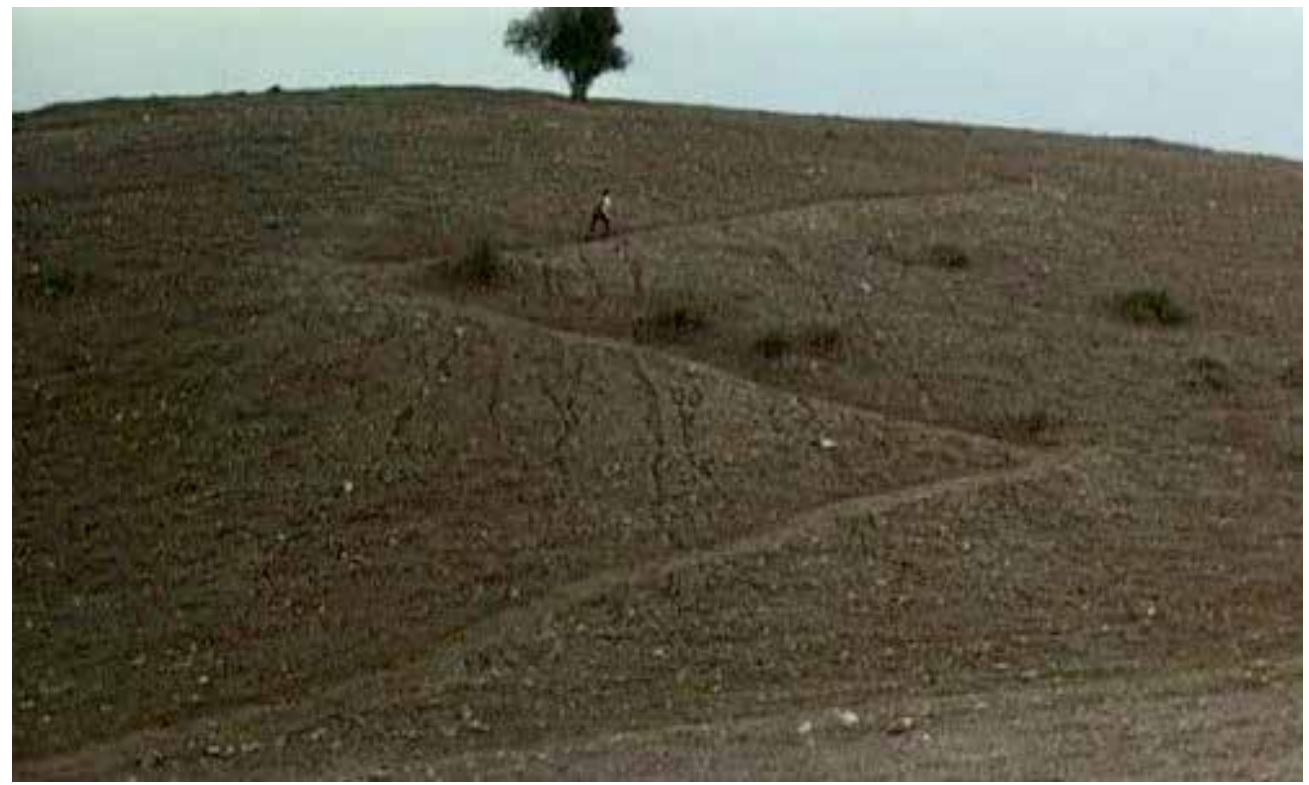

Fonte: Abbas Kiarostami, 1987

Para a sua sorte, ele reconhece outro amigo de escola, que lhe informa onde mora o primo de Mohammed, chamado Hematí: no distrito de Khanevar, no alto de uma rua e perto de um portal azul. Novamente, Ahmed prossegue em direçáo a ruas e becos até que para na porta de uma casa e vê no varal uma calça marrom parecida com a de seu amigo. Ele corre em direçáo ao objeto que lhe é tâo familiar e o toca por alguns minutos, tentando estabelecer uma relação com a calça que, na sua cabeça, pertence ao colega. Ahmed bate em uma porta e chama por Mohammed, mas o único que atende os seus chamados é um gato. O garoto percorre a vizinhança perguntando de quem é a calça marrom pendurada no varal. Bate em uma casa vizinha e quem atende é uma idosa que responde não conhecer ninguém chamado Mohammed Nematzadeh.

Toda esta trajetória, o mau humor de algumas pessoas, a falta de solidariedade e o fato de ninguém o escutar, nada faz Ahmed desistir. Ele não perde a esperança. Eventualidades surgem para tirar Ahmed de seu objetivo de entregar o caderno, como todo bom herói que é tentado a sair de seu foco ou destino. O menino usa um processo criativo de movimentação e improvisação para resolver uma problemática, e cada nova pista sobre a casa de seu amigo o impulsiona a continuar.

Quando lemos sobre os grandes heróis da mitologia grega, por exemplo, Hércules - conhecido comumente apenas por sua força e virilidade -, percebemos que ele falhava em sua jornada toda vez que utilizava a força em detrimento da 
inteligência. Ahmed não possui a força de Hércules, mas mesmo pequeno é capaz de pensar em soluçóes e estratégias para devolver o caderno de seu amigo. Durante o percurso, encontra um comerciante chamado Nematzadeh e deduz que ele seja parente de Mohammed por ter o mesmo sobrenome. Ahmed segue o desconhecido com o intuito de cumprir o seu objetivo maior, crente de que está avançando na sua jornada. Contudo, à medida que o segue, descobre que o comerciante não é nada para Mohammed, ou seja, não existia a conexão imaginada pelo menino entre o desconhecido e o seu amigo.

Em certos pontos da narrativa fílmica, Kiarostami insere elementos como a calça e o sobrenome de um desconhecido como ícones para que Ahmed fale de sua relação com o amigo, sendo necessário reiterar, para cada pessoa que encontra, o fato de que precisa devolver o caderno. $\mathrm{O}$ simbólico aqui utilizado é o "objeto, ato, acontecimento, qualidade ou relação que serve como veículo a uma concepção" (Geertz, 2008:67). Tanto a calça quanto o sobrenome de um desconhecido funcionam como uma forma de Ahmed falar de sua relação com o amigo, mas também são fontes de informaçáo para o menino na medida em que são as únicas pistas que o fazem achar que está próximo de concretizar a sua jornada - ou seja, criam novas relaçôes.

\section{Figura 6 - Ahmed seguindo um provável parente de Mohammed}

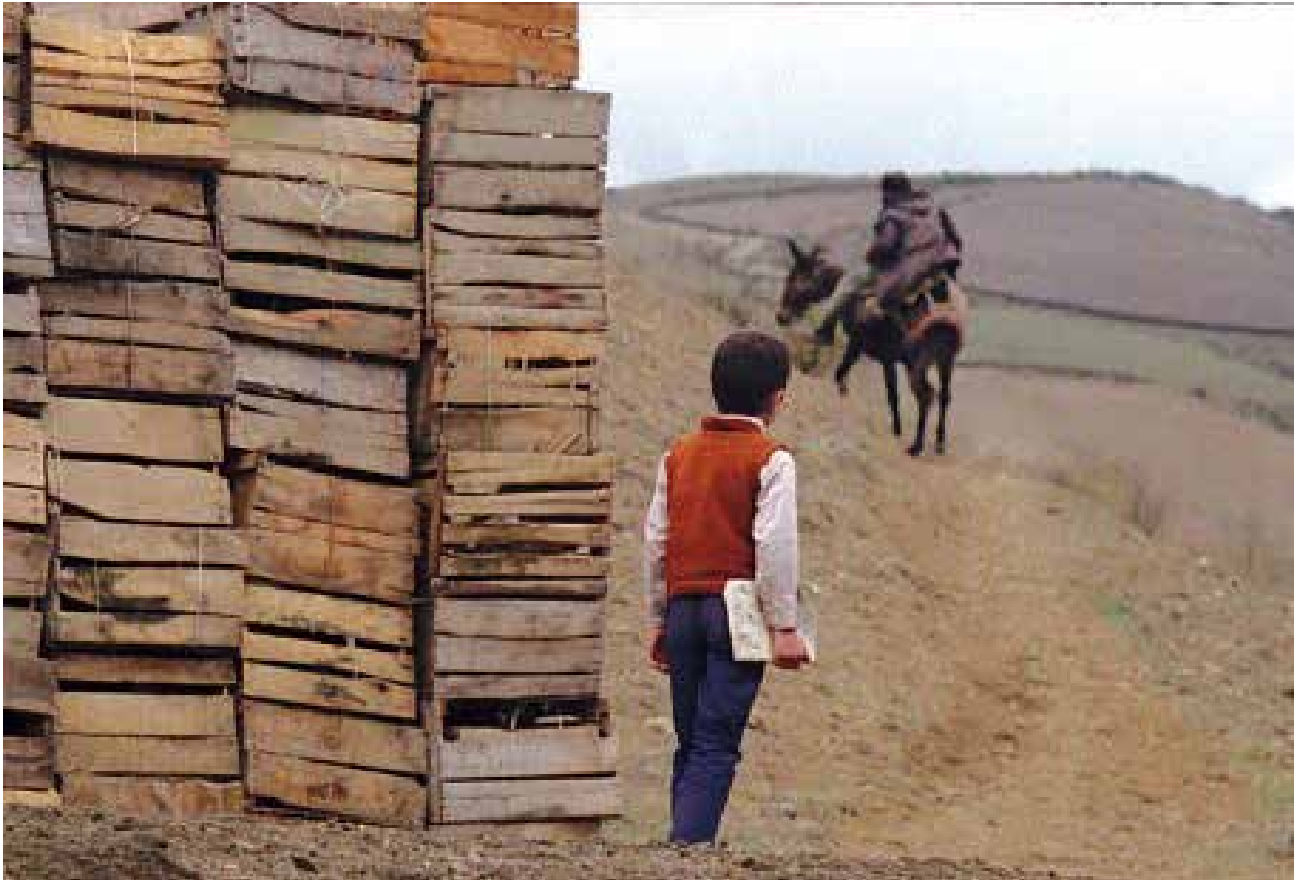

Fonte: Abbas Kiarostami, 1987

Anuário Antropológico, Brasília, UnB, 2017, v. 42, n. 1: 87-109 
Ahmed descobre caminhos, conhece pessoas e interage com coisas. Constrói uma cartografia de suas idas e subidas, becos, ruas, escadarias e declives, explorando a geografia de uma regiáo que ele desconhecia. Provavelmente, o garoto não iria vivenciar na escola esse conhecimento, pois na obra ficcional de Kiarostami os "lugares não têm posiçôes e sim histórias" (Ingold, 2005:77). Estes lugares são

unidos pelos itinerários de seus habitantes, os lugares existem não no espaço, mas, como nós, em uma matriz de movimento. Chamarei essa matriz de "regiáo". É o conhecimento da região, e com isso a habilidade de uma pessoa situar-se na sua posição atual dentro do contexto histórico de jornadas efetuadas anteriormente - jornadas para lugares, de lugares e em volta de lugares (Ingold, 2005:77).

Para o jovem Ahmed não existem distâncias, fronteiras ou até mesmo o cansaço físico. Ele corre de um vilarejo para o outro, fala com as pessoas explicando o seu dilema, isto é, conta a sua história. Ele não precisa de um mapa para andar de um vilarejo para o outro. O menino se deixa levar por um fluxo de coisas e pessoas se movendo de um lugar para o outro sem se perder no percurso, pois sabe onde está:

não porque aquilo que vemos à nossa volta confere com uma determinada imagem mental, mas porque essa determinada imagem deriva de um mapa subjacente, em um ponto definido por determinado conjunto de coordenadas espaciais que são indiferentes ao nosso próprio movimento. Quando passamos de um lugar para o outro, passamos através de uma sequência de imagens, cada qual sendo especifica a uma determinada localização em nosso caminho, e que, por sua vez nos permite a sua identificação (Ingold, 2005:82).

Os lugares são não lugares, ou seja, não são determinados e passíveis de deslocamento - Ahmed não está em apenas um lugar, mas em toda parte. $\mathrm{O}$ caminho percorrido pelo menino introduz o espectador na trilha da regiáo dos vilarejos de Poshter e Koker: "uma trilha compreendida não como uma série infinita de pontos discretos, ocupados em instantes sucessivos, mas como um itinerário contínuo de movimento" (Ingold, 2005:86). É esta movimentação que o faz prosseguir com o seu objetivo, bem como as informaçóes nada precisas de um colega de escola, de um idoso e de uma calça marrom. São as conexóes que ele estabelece entre coisas e pessoas que o impulsionam a estar sempre a um passo de encerrar a sua jornada. 


\section{Objeto em movimento e criaçáo de relaçóes sociais}

Com poucos diálogos, o cineasta iraniano trabalha com muitos sons, como o arrastar dos sapatos de Ahmed no chão, o miado de um gato, o barulho d'água correndo como um fluxo etc. Algumas situaçóes e o aparecimento de alguns personagens sem diálogos passam exatamente pela enunciação dos sons. $\mathrm{O}$ som, desta forma, traz realismo à trama na medida em que fornece contexto às experiências apresentadas. Kiarostami também registra o deslocamento de objetos, animais e pessoas como forma de nos imergir na angústia do personagem e nos apresentar a geografia do lugar na medida em que caminhamos com seu protagonista.

O sentimento de angústia paira por quase todas as cenas, desde a abertura, quando Kiarostami traz o close de uma porta e, ao fundo, ouvimos o som de várias crianças falando ao mesmo tempo, o que nos leva a deduzir que se trata de uma escola ou de uma sala de aula. O segundo close é feito no menino Mohammed, quando ele começa a chorar após a bronca do professor por ter feito as suas atividades em um papel avulso. Kiarostami gosta de trabalhar com uma câmera fixa, que registra paisagens, adultos (como pessoas superiores em relação às crianças) e objetos que se tornam animados ao iniciar um processo de agenciamento nas relaçôes dos personagens.

A função do caderno enquanto objeto, inicialmente, é nos situar em um ambiente de repressão e opressão da cultura infantil - talvez um significado metafórico lançado para que nós mesmos possamos refletir sobre o universo infantil e a nossa postura cotidiana de ignorar as crianças e suas experiências.

O diretor sempre nos frustra fazendo-nos acreditar momentaneamente que Ahmed está próximo de cumprir a sua missão. Por exemplo, ao seguir um possível parente de Mohammed, Ahmed vê um garoto cujo rosto está escondido por carregar uma porta de madeira, mas que está usando a mesma calça de seu amigo. Nesta cena, acreditamos que Ahmed finalizou o seu objetivo. Mera ilusão, pois quando o garoto se livra do objeto que oculta o seu rosto descobrimos que aquele não é Mohammed.

O caderno é um gatilho para que o personagem construa uma malha de interaçóes e conexóes descrevendo um conjunto de movimentos dentro do qual se dá a sua prática de aprendizado sobre outros objetos, lugares e pessoas. Para Ingold, "como a pipa, o ser humano náo é um ser que age - um agente -, mas um ramo de atividade, energizada pelos fluxos de materiais, incluindo as correntes de ar, que percorrem o corpo e, através de processos de respiração e metabolismo, mantém-no vivo" (2013:316). ${ }^{7}$ 
O exemplo da pipa descrito por Ingold é sobre como a interação de entidades, sejam elas sociais ou não, surge como trajetórias de movimento e impacta significativamente nossas vidas. Assim, tanto o caderno quanto Ahmed traçam uma cadeia de conexóes, pois ambos nunca estáo parados, sempre estáo circulando por entre lugares e compondo pessoas. O esquema a seguir representa a movimentação e as relaçóes estabelecidas pelo personagem.

\section{Figura 7 - A movimentaçáo de Ahmed e as relaçóes sociais estabelecidas pelo personagem}

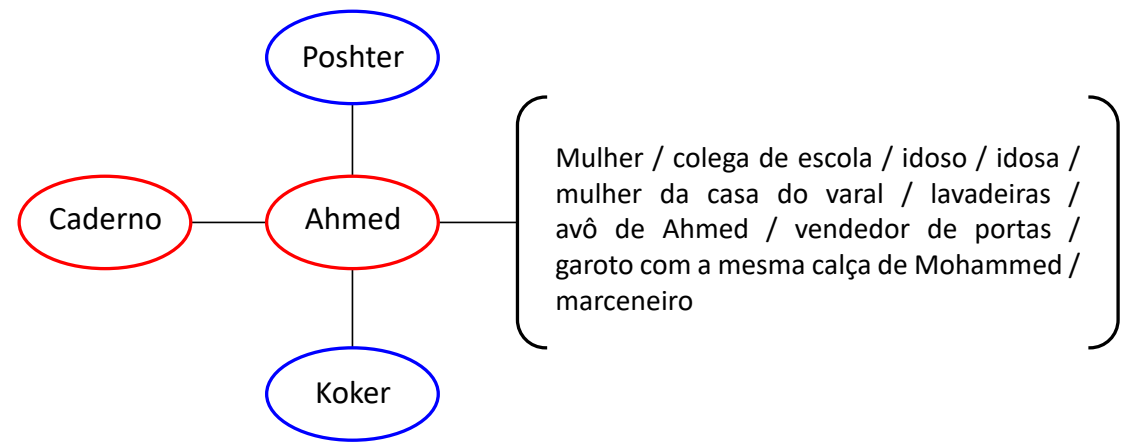

Fonte: elaboração própria

Kiarostami traz em seu enredo uma criança que não se importa de caminhar ou correr por caminhos tortuosos por sentir solidariedade e preocupação com o seu amigo de escola. O caderno está na trama para representar a cumplicidade entre crianças e revelar um grande controle existente entre adultos e crianças. $\mathrm{O}$ diretor se mostra insatisfeito com uma cultura que coloca o adulto como opressor e a criança como impotente.

Toda esta movimentação de Ahmed transformou-o de maneira significativa. Esse vai e vem de coisas e pessoas faz com que ele aprenda o jogo e as regras do mundo adulto. $\mathrm{O}$ menino chega a uma suposta casa que seria de seu amigo acompanhado de um velho marceneiro. Mas já está tarde. $\mathrm{O}$ vento forte ameaçador anuncia uma terrível chuva e ele desiste de bater na porta. O garoto volta desolado para casa, se rende ao cansaço e à frustração de náo ter cumprido com êxito a sua jornada. Ele compreende que o caderno e a sua tentativa malsucedida de devolvê-lo para o amigo são um problema insolúvel. E se resigna a uma cultura de invisibilidade em que quase ninguém se compadece de sua história. Resolve, entâo, agir de acordo com as leis impostas por uma sociedade adulta. Deixa-se levar pela "má-fé": faz os seus deveres e o de seu amigo Mohammed, salvando-o de uma expulsão. 
A jornada de Ahmed e o seu objetivo não se finalizam com êxito, no entanto, o menino já não é o mesmo. As pessoas que ele encontra, a movimentação que faz e as relaçóes que estabelece culminam em uma aprendizagem. Para Ramon Sarró (2009), falar dos deslocamentos como aventura é colocar sujeitos (e aqui poderíamos também pensar em objetos) como agentes que permitem a comunicação entre mundos e espaços que não se conhecem, mas se tornam conectados. Nesse sentido, Ahmed "não é a fonte de um alvo e sim o alvo móvel de um amplo conjunto de entidades que enxameiam em sua direção" (Latour, 2012:75).

\section{Figura 8 - A cadeia de relaçóes sociais que Ahmed faz para entregar o caderno de seu amigo}

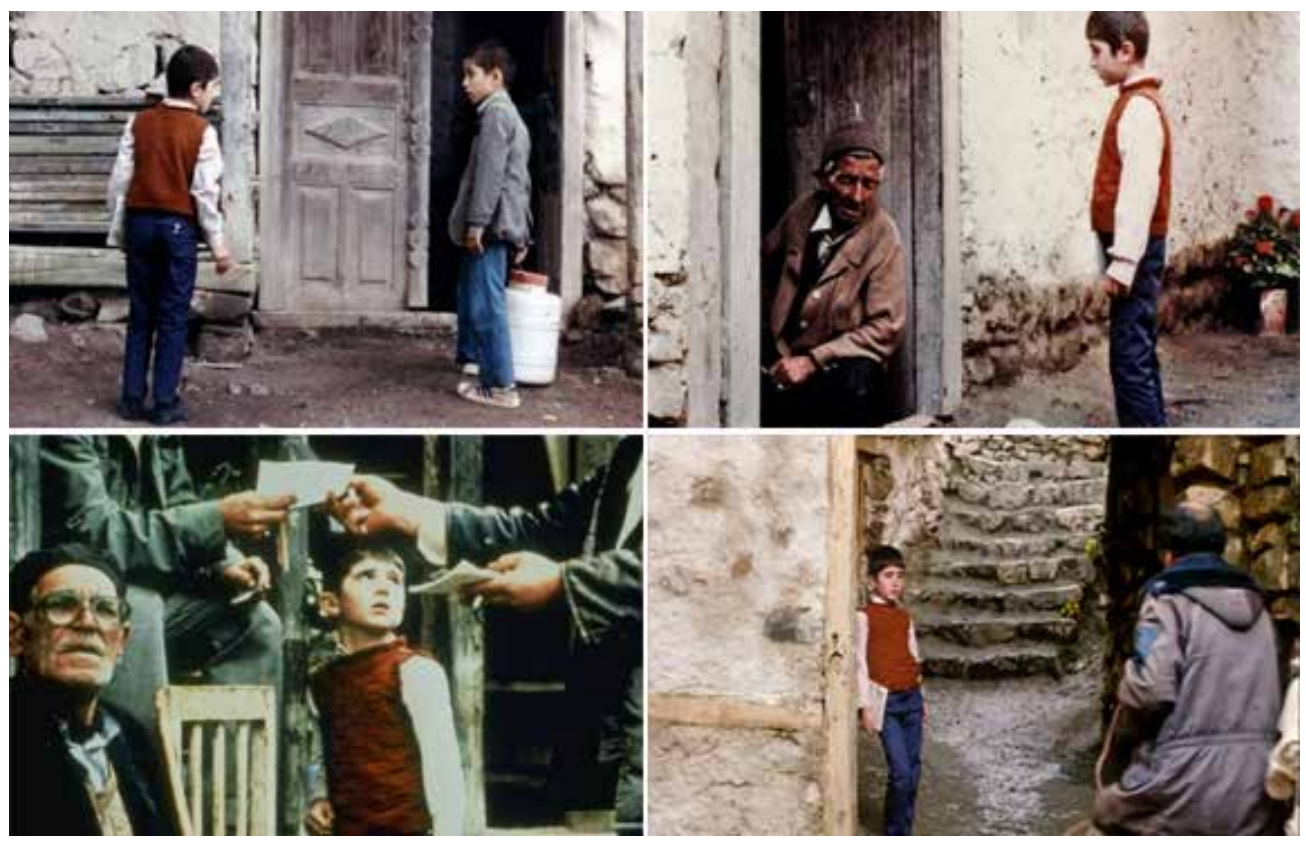

Fonte: Abbas Kiarostami, 1987

\section{Consideraçóes finais}

A cinematografia de Kiarostami nos introduz à construção de uma infância portadora de significado e contribui para a desconstrução de uma cultura infantil única e uniforme, revelando o que há de mais agridoce na relação entre crianças e adultos, as formas de tratamento, a opressão e a submissão. Toda a narrativa lírica do diretor iraniano é construída em um ambiente de poucos recursos, pobreza e censuras. $\mathrm{O}$ único desejo de Ahmed é devolver o caderno de seu amigo, mas as 
adversidades são tantas que ele acaba se rendendo ao cansaço e à frustração. Não é o objeto que exerce esse sentimento no personagem, mas as tentativas falhas, as pessoas e as experiências frustradas.

Resta-nos perguntar duas coisas: o porquê de Ahmed não ter feito o seu exercício e o de seu amigo logo de início, sem precisar passar por tantas adversidades, e se há diferenças ou particularidades na apropriação que crianças e adultos fazem dos objetos - ou de um mesmo objeto, como o caderno. Na narrativa fílmica de Kiarostami, Ahmed inicialmente aparenta ser uma criança iraniana invisível aos olhos dos adultos, mas é capaz de se sensibilizar com o amigo que está prestes a ser expulso da escola por não ter feito as suas atividades em um caderno, como o professor havia ordenado. $\mathrm{Na}$ trama, crianças e adultos se apropriam de formas divergentes de um mesmo objeto, o caderno. Para Ahmed, o caderno serve como uma forma de falar de sua relação com o amigo e de contar a sua história. Para o professor, é uma forma de controle, avaliação e verificação da aprendizagem.

O objeto (caderno) proporciona a Ahmed conhecer diferentes lugares e pessoas. Também faz com que o menino utilize certas estratégias comunicativas para ser compreendido, ouvido e entendido, e acima de tudo tentar superar o ponto de tensão do filme: a entrega do caderno para o seu amigo Mohammed. Portanto, o cinema realista e minimalista de Kiarostami reflete sobre os grandes dilemas da ação humana.

Talvez se o menino tivesse seguido outro caminho ou encontrado outras pessoas, o sentimento de frustração e de derrota não o teria abalado, e ele conseguiria finalizar a sua jornada com êxito. Cansado de suas falhas, Ahmed se deixou influenciar pelas noçóes de censura de seus pais, seu medo e seu espanto. Sujeitou-se pela força das circunstâncias, passando por uma sequência de pequenas provas para se preparar para a vida de adulto: é como, insistentemente, a sociedade dos adultos incide sobre a infância.

Recebido em 10/1/2017

Aprovado em 14/11/2017 
Marília Milhomem Moscoso Maia é mestra em cultura e sociedade pela Universidade Federal do Maranhão e professora concursada de séries iniciais do município de Paço do Lumiar (MA). Contato: mariliamilhomem@gmail.com

Martina Ahlert é doutora em antropologia social pela Universidade de Brasília e professora da Universidade Federal do Maranhão. Contato: ahlertmartina@ gmail.com

\section{Notas}

1. Por viés positivista nos referirmos à abordagem proveniente dos estudos de Auguste Comte, que sugere a existência de leis imutáveis universais e que propóe o conhecimento científico como único conhecimento verdadeiro.

2. Vale destacar aqui a linguagem cinematográfica como forma de construção e representação de uma realidade: "seja através da reconstrução do passado ou do futuro do pretérito, os filmes nos possibilitam revisitar os eventos ocorridos ou imaginados. As transposiçóes e as vivências que a linguagem cinematográfica possibilita são tão marcantes, que muitas vezes tornam-se referência de como a ciência e a técnica passam a percebidas por grande parte da sociedade. Mais do que aprendizagens derivadas das práticas educativas formais, as experiências vivenciadas nos filmes acabam compondo boa parte do arsenal simbólico através do qual a opinião pública passa a vislumbrar o alcance dos empreendimentos científicos e tecnológicos" (Oliveira, 2006:134).

3. Trata-se das manifestações que iniciaram em 1978 e que, no início do ano seguinte, levaram o Irã a ser declarado como República Islâmica.

4. No original, "instead of subjects and objects there are 'quasi-objects' and 'quasisubjects, connected in relational networks" (Ingold, 2011:11).

5. Latour (2012:65) ainda utiliza dois termos para explicar os meios de produzir o social que nos ajudam a entender os objetos como sujeitos de ação, os intermediários e mediadores: "um intermediário é aquilo que transporta significado ou força sem transformá-los: definir o que entra já define o que sai. Um intermediário pode ser considerado não apenas como uma caixa-preta, mas uma caixa-preta que funciona como uma unidade, embora internamente seja feita de várias partes. Os mediadores, por seu turno não podem ser contados como apenas um, eles podem valer por um, por nenhuma, por várias ou uma infinidade. O que entra neles nunca define exatamente o que sai; sua especificidade precisa ser levada em conta todas as vezes".

6. No original, "about the ways in which substances of all sorts, enlivened by cosmic forces and with variable propertis, mix and meld with one another in the generation of things" (Ingold, 2013:313).

7. No original, "like the kite, the human is not a being that acts - an agent - but a hive of activity, energized by the flows of materials, including the currents of air, that courses through the body and, through processes of respiration and metabolism, keep it alive" (Ingold, 2013:316). 


\section{Referências}

ARIÈS, Philippe. 1978. História social da criança e da família. 3 ed. Rio de Janeiro: S.A.

BERGALA, Alain. 2008. A hipótese-cinema. Tradução de Mônica Costa Netto e Silvia Pimenta. Rio de Janeiro: Booklink; Cinead-Lise-FE/UFRJ.

COHN, Clarice. 2005. Antropologia da criança. 2. ed. Rio de Janeiro: Zahar.

COUTINHO, Ângela Maria Scalabrin. 2003. "Culturas infantis: conceitos e significados no campo da pesquisa e no cotidiano da educação infantil”. Zero-a-Seis, 5(7):46-56.

FOUCAULT, Michel. 2015. História da sexualidade: a vontade de saber. v. 1. 3. ed. São Paulo: Paz e Terra.

GEERTZ, Clifford. 2008. A interpretação das culturas. Rio de Janeiro: LTC.

INEZ, Ana Marta Aparecida de Sousa \& FARIA, Vitória Líbia Barreto de. 2006. "O balão branco: encontros e encantos pelos cantos da cidade". In: Inês Assunção de Castro Teixeira, Jorge Larrosa \& José de Sousa Miguel Lopes (org.). A infância vai ao cinema. Belo Horizonte: Autêntica. pp. 193-208.

INGOLD, Tim. 2005. "Jornada ao longo de um caminho de vida - mapas, descobridorcaminho e navegação”. Religião e Sociedade, 25(1):76-110.

. 2012. "Trazendo as coisas de volta à vida: emaranhados criativos num mundo de materiais". Horizontes Antropológicos, (37):25-44.

. 2013. "Making, growing, learning: two lectures presented at UFMG". Educação em Revista, 29(3):301-323.

KIAROSTAMI, Abbas. 1987. Onde fica a casa do meu amigo?(Khane - ye doust kodjast?). Irã.

LATOUR, Bruno. 2012. Reagregando o social. Salvador: Edufba.

MELEIRO, Alessandra. 2006. O novo cinema iraniano: arte e intervenção social. São Paulo: Escrituras.

MERENCIO, Fabiana Terhaag. 2013. "A imaterialidade do material, a agência dos objetos ou as coisas vivas: a inserção de elementos inanimados na teoria social”. Lepaarq (Laboratório de Antropologia e Arqueologia - UFPel), 10(20):1-22.

OLIVEIRA, Bernardo Jefferson de. 2006. "Cinema e imaginário científico". História, Ciências, Saúde-Manguinhos, 13(suplemento):133-150. 
PIRES, Eloiza Gurgel. 2011. "Cinema e educação: o deslocamento poético do olhar na construçáo do conhecimento". Revista Universitária do Audiovisual. Disponível em: http://www.rua.ufscar.br/site/?p=3823. Acesso em: 28/05/2014.

SARRÓ, Ramon. 2009. "La aventura como categoría cultural: apuntes simmelianos sobre la emigración subsaariana”. Revista de Ciências Humanas, 43(2):501-521.

TASSINARI, Antonella. 2009. "Múltiplas infâncias: o que a criança indígena pode ensinar para quem já foi à escola ou a sociedade contra a escola". Anais do $33^{\circ}$ Encontro Anual da ANPOCS. Caxambu, 26 a 30 de outubro de 2009.

WAGNER, Roy. 2010. A invenção da cultura. São Paulo: Cosaic Naify. 


\section{Resumo}

Este artigo discorre sobre o conceito de agência e pensa como um simples objeto, um caderno, orquestra a saga e as açóes do personagem Ahmed no filme Onde fica a casa do meu amigo, do diretor iraniano Abbas Kiarostami. Para tal, inspiramo-nos no conceito de cultura de Geertz (2008) para a compreensão do que se considera culturas infantis, e sobretudo em autores como Latour (2012) e Ingold (2005, 2012, 2013), entre outros, para compor as categorias de análise para a investigação desse filme. Além disso, dado o nosso foco de análise - agência -, baseamo-nos em autores que investigam a cultura e como estes estudos auxiliam na discussão de uma cultura infantil baseada na interação criança-criança, criançaadulto, criança-objeto e criança-espaço, representada na ficção de Kiarostami. Os objetos assumem um papel central nessa discussão sobre a infância no Irã contemporâneo.

\section{Abstract}

This paper analyses the concept of agency and reflects on how a simple object, a notebook, orchestrates the story and the actions of the character Ahmed in the film Where is the friend's home? (1987), directed by Iranian filmmaker Abbas Kiarostami. Geertz's (2008) concept of culture is used to understand what is considered as the children's cultures, and authors such as Latour (2012) and Ingold (2005, 2012, 2013) inspire the categories of analysis applied to this film. Moreover, given the focus of this analysis, agency, the suggested authors aid in the discussion of children's culture, based on childchild, child-adult, child-object, and child-space interactions represented in Kiarostami's film. The objects play a central role in this discussion about childhood in contemporary Iran.

Key-words: agency, childhood, object.

Palavras-chave: agência, infância, objeto. 